\title{
VIABILIDADE ECONÔMICO-FINANCEIRA DA IMPLANTAÇÃO DA CULTURA DO MILHO NO MUNICÍPIO DE SANTA TERESA-ES
}

\section{ECONOMIC AND FINANCIAL VIABILITY OF THE IMPLEMENTATION OF CORN CULTURE IN THE MUNICIPALITY OF SANTA TERESA-ES}

\author{
Bruno Estáquio Cirilo Silva ${ }^{1}$ \\ Marlinda Rufina Jolomba Silva²
}

Resumo: A importância econômica do milho é caracterizada pelas diversas formas de sua utilização, que vai desde a alimentação animal até a indústria de alta tecnologia. O milho se destaca como um produto agrícola de grande importância no cenário brasileiro, sendo utilizado desde a produção animal, passando pelo aspecto social. O Brasil é um dos maiores produtores de milho do mundo, ficando atrás dos Estados Unidos e da China. A safra de milho (Zea mays L.) vem crescendo a cada ano no Brasil, em produção e em área plantada: esse cereal pode ser produzido em todo o território brasileiro e seu rendimento é de 5,4 tha1. No Espírito Santo, o milho é cultivado pelos agricultores familiares, em uma área de 40 mil hectares e utilizado, principalmente, e no consumo familiar - na alimentação de aves, suínos, bovinos e no agroturismo. O presente trabalho tem o objetivo de implantar a cultura do milho no Instituto Federal de Educação, Ciência e Tecnologia do Espirito Santo - Campus Santa Teresa, para fins de produção de silagem para alimentação animal, verificado sua viabilidade econômica.

Palavras-chave: Custo de produção; renda bruta total; renda líquida.

\begin{abstract}
The economic importance of corn is characterized by the diverse forms of its use, ranging from animal feed to the high technology industry. Maize stands out as an agricultural product of great importance in the Brazilian scenario, being used from animal production, meeting the social aspect. Brazil is one of the largest corn producers in the world, behind the United States and China. Corn crop (Zea mays L.) has been growing every year in Brazil, in both production and planted area: this cereal can be produced all over Brazil and its yield is $5.4 t_{\text {ha- }}{ }^{1}$. In the state of Espírito Santo, corn is cultivated by family farmers in an area of 40,000 hectares and used mainly for family consumption - in the feeding of poultry, pork, cattle and in agrotourism. The present work has the objective of implanting corn crop in the Federal Institute of Education, Science and Technology of Espírito Santo - Santa Teresa Campus, for the purpose of silage production for animal feed, verifying its economic viability.
\end{abstract}

Keywords: Production cost; total gross income; net income.

\section{INTRODUÇÃO}

O milho é cultivado há pelo menos 5000 anos. Possivelmente, sua origem seja do México, América Central ou Sudoeste dos Estados Unidos. Após sua descoberta, foi levado para a Europa, tornando-se conhecido como alimento, a partir daí expandiu-se por todo o globo (DUARTE; GARCIA; MIRANDA, 2011). A cada ano, a produção vem crescendo seguindo o avanço das pesquisas. O milho é uma das principais culturas instaladas no Brasil e há vários trabalhos envolvendo essa espécie; assim, atualmente, diversas variedades existem no mercado.

\footnotetext{
${ }^{1}$ Graduado em Agronomia pela Universidade Federal de Viçosa, MG, Brasil. E-mail: brunomukuri@gmail.com.

2 Graduada em Medicina Veterinária pela Faculdade de Medicina do Huambo - Angola. Mestre em Zootecnia Universidade Federal de Viçosa, Brasil. E-mail: marjolomba29@gmail.com.
} 
Essa cultura é utilizada pelo homem há muito tempo, o seu aproveitamento vai deste à alimentação humana ou animal até a utilização da palha para o artesanato. Em geral, grande parte do milho em grão é destinada para a alimentação animal, cerca de $70 \%$ no mundo. O Brasil destina entre 60 e $80 \%$ de sua produção (milho em grão), por ano, para este fim (DUARTE; GARCIA; MIRANDA, 2011). Na região nordeste, o milho representa um alimento muito importante na mesa da população mais carente, sendo utilizado em várias receitas.

Segundo dados do Departamento de Agricultura dos Estados Unidos (USDA), na safra 2013/14, o milho foi o grão mais produzido no mundo. Somente na safra 2013/14 foram produzidos 988 milhões de toneladas. Os principais produtores são Estados Unidos e China, com $36 \%$ e $22 \%$ da produção mundial, respectivamente. O Brasil é o terceiro maior produtor, com $8 \%$. Os principais consumidores também são os Estados Unidos e a China, com 295 e 212 milhões de toneladas, respectivamente. Em terceiro lugar está a União Europeia, com 76 milhões e em quarto o Brasil, com 55 milhões. Apesar de estar entre os três maiores produtores, o Brasil não se destaca entre os países com maior produtividade. Porém a produtividade brasileira tem crescido sistematicamente, passando de $1841 \mathrm{~kg} \mathrm{ha}^{-1}$, na safra 1989/90, para $3972 \mathrm{~kg} \mathrm{ha}^{-1}$, na safra 2007/08; e $5383 \mathrm{~kg} \mathrm{ha}^{-1}$, na safra 2016/2017 (CONAB, 2017). A baixa produtividade média de milho no Brasil não reflete o bom nível tecnológico já alcançado por boa parte dos produtores voltados para lavouras comerciais, uma vez que as médias são obtidas nas mais diferentes regiões, em lavouras com diferentes sistemas de cultivos e finalidades (DUARTE; GARCIA; MIRANDA, 2011, 2011).

Para assegurar o rendimento na produção de milho, deve-se ficar atento a vários fatores importantes, tais como a interceptação de radiação solar pelo dossel, eficiência metabólica, eficiência de translocação de fotoassimilados para os grãos e a capacidade de dreno. As plantas procuram se adaptar às condições ambientais, respondendo de formas diferenciadas dos genótipos e a variação ambiental. As variações ambientais são imprevisíveis e, por isso, a escolha da época de plantio, por exemplo, é difícil de ser determinada para cada cultivo, a fim de que esta responda da melhor forma possível.

No Espírito Santo, o milho é cultivado pelos agricultores familiares, tendo uma área de 40 mil hectares e utilizado, principalmente, no consumo familiar, na alimentação de aves, suínos, bovinos e no agroturismo (FERRÃO, 2013).

O milho se destaca como um produto agrícola de grande importância no cenário brasileiro, sendo utilizado desde a produção animal, passando pelo aspecto social, pois grande parte dos produtores não é tecnificada, não possui grandes extensões de terras, mas dependem dessa produção para viver. Isso pode ser constatado pela quantidade de produtores que consomem o milho na propriedade. O presente trabalho teve por objetivo implantar a cultura do milho no Instituto Federal de Educação, Ciência e Tecnologia do Espirito Santo - Campus Santa Teresa, para fins de produção de silagem para alimentação animal, verificado sua viabilidade econômica. 


\section{MATERIAL E MÉTODOS}

O presente trabalho foi conduzido no Instituto Federal de Educação, Ciência e Tecnologia do Espirito Santo - Campus Santa Teresa, localizado no distrito de São João de Petrópolis, Santa Teresa-ES, nas coordenadas geográficas: latitude de 1981'Sul e longitude $40^{\circ} 68^{\prime}$ Oeste e altitude de $150 \mathrm{~m}$. A temperatura média anual é de $26,5^{\circ} \mathrm{C}$ e a pluviosidade situa-se entre 900 a $1200 \mathrm{~mm}$.

Figura 1. Foto aérea do IFES. Área do pivô em destaque.

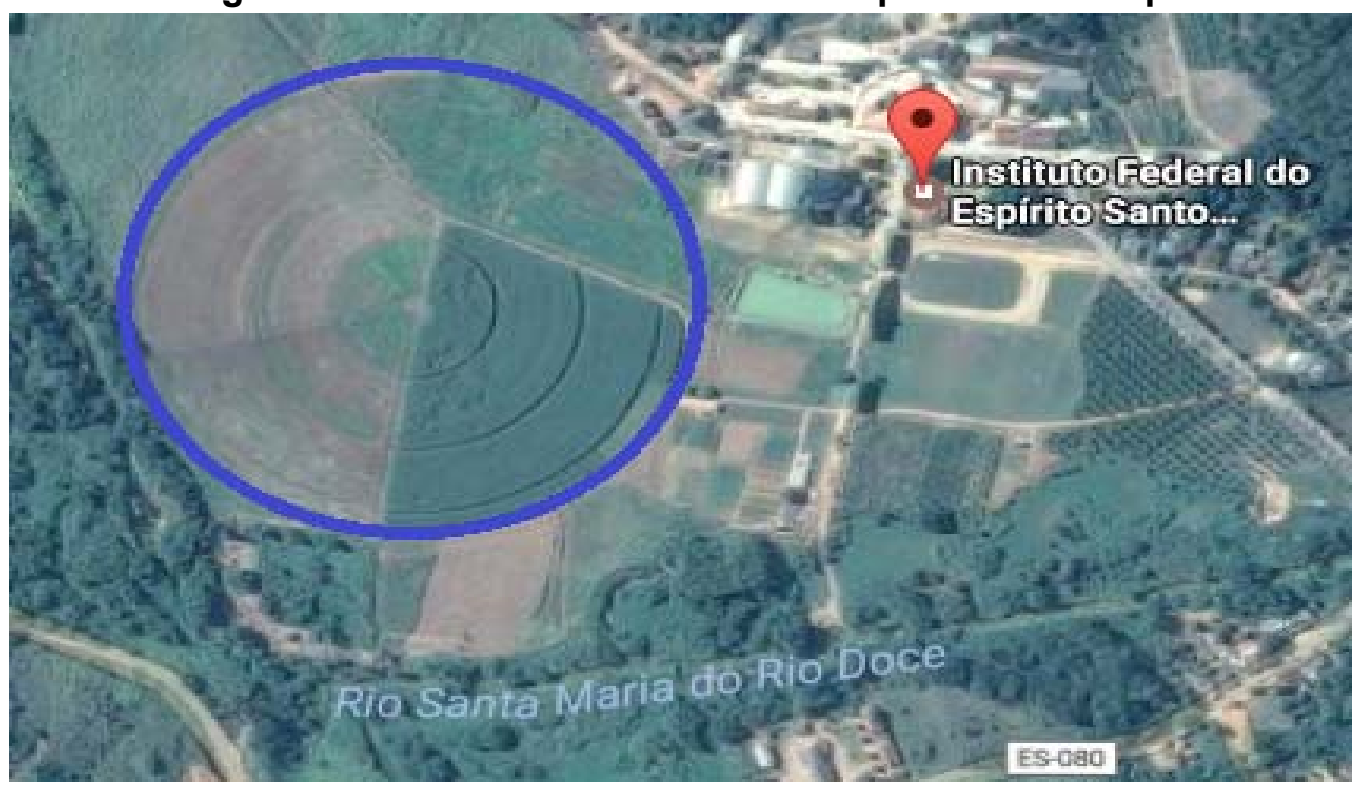

Fonte: Google maps.

Foi feito o planejamento para aumentar a produção e reduzir os custos, planejamento para a aquisição de implementos, produtos fitossanitários e insumos agrícolas e o acompanhamento da lavoura durante todo o seu desenvolvimento, sendo feitas as devidas interferências em cada fase da cultura.

A necessidade hídrica foi suprida com a captura de água do rio Santa Maria do Rio Doce, que corta a propriedade. O sistema de irrigação utilizado foi por aspersão tipo pivô central. Foi adquirido um pivô central da marca Fokink, de 12,0 ha de área irrigada composto por três torres. O sistema de pivô central foi equipado com aspersores Super Spray, com tubo de descida flexível. O comprimento total (raio) é 195,8 m, sendo o comprimento até a última torre de $178,5 \mathrm{~m}$ e o vão de balanço com $16 \mathrm{~m}$. O conjunto moto-bomba consta com uma bomba centrífuga de rotação 1750 RPM, vazão 44,00 $\mathrm{m}^{3} / \mathrm{h}$, 2 estágios, consumindo 8,48Kw/h. O motor é elétrico, trifásico, com 220 volts, 12,5 cv e 1750 rpm. A implantação do pivô central custou $R \$ 109.000,00$, sendo $R \$ 9.083,33$ por hectare.

A fim de aumentar o potencial de produção quando às condições hídricas, fertilidade do solo e controle de pragas, entre outros fatores, são otimizadas, procurouse utilizar o cultivar 'Capixaba Incaper 203'. A 'Capixaba Incaper 203' apresenta alta 
produtividade, boa estabilidade de produção, bom empalhamento de espiga e tolerância às principais doenças foliares e de grãos, à seca e ao acamamento e quebramento de plantas.

A cultura do milho sofre com danos causados pelas pragas desde a fase vegetativa até a reprodutiva. Os danos variam de acordo com o estádio fenológico da planta, condições edafoclimáticas, sistemas de cultivo e fatores bióticos localizados, sendo atacada por várias espécies de pragas. As principais pragas da cultura do milho são: na Fase Vegetativa: Lagarta-do-cartucho (Spodoptera frugiperda), Curuquerê-doscapinzais (Mocis latipes), Broca da cana-de-açúcar (Diatraea saccharalis), Cigarrinhado-milho (Dalbulus maidis); e Na Fase reprodutiva: Lagarta-do-cartucho (Spodoptera frugiperda), Lagarta-da-espiga (Helicoverpa zea) (CRUZ; VIANA; WAQUIL, 2013).

A mancha branca, a cercosporiose, a ferrugem polissora, a ferrugem tropical, a ferrugem comum, a helmintosporiose e os enfezamentos pálido e vermelho estão entre as principais doenças da cultura do milho (CASELA; FERREIRA; PINTO, 2006).

Por meio de uma prévia análise do solo, foram efetuados cálculos de calagem e adubação para a adequação dos níveis de nutrientes no solo para a cultura do milho.

O cultivo será efetuado no sistema de plantio direto (SPD). Para o estabelecimento do sistema de plantio direto, foi realizado o preparo do solo destinado à sua descompactação, seguindo a incorporação do calcário para correção da acidez. Dessa forma, o primeiro cultivo de milho foi realizado em solo desnudo, já, no segundo ciclo de produção, a área já contará com plantio de feijão para o estabelecimento da cobertura vegetal ou palhada.

A vegetação de cobertura foi composta pela própria vegetação infestante da área. O manejo da cobertura foi realizado com roçagem, ou rolo faca e dessecantes químicos.

Conforme os resultados da análise de solo, presentes na Tabela 1, o solo da área é de textura Franco argilo arenoso e seu pH em $\mathrm{H}_{2} \mathrm{O}$ está na faixa de 6,3.

Tabela 1. Resultado da análise granulométrica

\begin{tabular}{|c|c|c|c|c|c|}
\hline \multirow{3}{*}{$\begin{array}{l}\text { Amostra } \\
\text { do solo }\end{array}$} & Areia grossa & Areia fina & Silte & Argila & Classificação textura \\
\hline & \multicolumn{4}{|c|}{$\%$} & \\
\hline & 39 & 21 & 8 & 32 & Franco argilo arenoso \\
\hline
\end{tabular}

Para esse tipo de solo, não foi necessária a adição de calcário, baseada no Método de Saturação de Bases para a cultura do milho irrigada.

A adubação de plantio foi baseada na análise da fertilidade do solo, no histórico de uso da área e na produtividade esperada. As tabelas de recomendação destinadas à cultura do milho se baseiam na produtividade esperada acima de $7.200 \mathrm{~kg} \mathrm{ha}^{-1} \mathrm{de}$ 
grãos. Para a adubação da cultura do milho em sistemas irrigados, utilizou-se a Tabela 2 de adubação de plantio e cobertura, recomendada por Prezzoti et al.(2007).

Tabela 2. Recomendações de adubação

\begin{tabular}{l|l|l|}
\hline Nutriente & \multicolumn{2}{|l|}{ Produtividade esperada (t/ha) } \\
\hline & $7.200 \mathrm{~kg} \mathrm{ha}^{-1}$ \\
\hline & Plantio & Cobertura \\
\hline Nitrogênio & $\mathrm{kg} \mathrm{ha}^{-1} \mathrm{de} \mathrm{N}$ \\
\hline & 10 a 15 & 100 a 120 \\
\hline Fosforo & $\mathrm{kg} \mathrm{ha}^{-1}{\mathrm{de} \mathrm{P}_{2} \mathrm{O}_{5}}$ \\
\hline Baixo & $100 \mathrm{a} 110^{2}$ & 0 \\
\hline Médio & 80 & 0 \\
\hline Alto & 50 & 0 \\
\hline Potássio & $\mathrm{kg} \mathrm{ha}^{-1}{\mathrm{de} \mathrm{K}_{2} \mathrm{O}}$ \\
\hline Baixo & 70 & 40 \\
\hline Médio & 50 & 20 \\
\hline Alto & 30 & 0 \\
\hline \multicolumn{2}{|l}{}
\end{tabular}

Conforme os resultados analíticos da amostra de solo, foram encontrados os seguintes resultados:

Com base na recomendação de Prezzoti et al. (2007), para a adubação nitrogenada, foi necessário aplicar $400 \mathrm{~kg}$ de ureia para os 12 hectares no plantio. Assim, foram adquiridos oito sacos de ureia para toda a área. A adubação de cobertura foi aplicada ao lado da linha de plantio, na dose de $12 \mathrm{~g}$ de $\mathrm{N}$ por metro linear.

Para a adubação fosfatada foram necessários $611,1 \mathrm{~kg} \mathrm{ha}^{-1} \mathrm{de} \mathrm{P}_{2} \mathrm{O}_{5}$. Dessa forma, para os 12 hectares, aplicaram-se aplicou $7.333,3 \mathrm{~kg}$ de superfosfato simples na linha de plantio.

Não foi necessária adubação de plantio e de cobertura com potássio, devido aos níveis no solo estarem suficientes. Também não houve necessidade de adubar com Manganês, Ferro, Zinco, Cobre, visto que esses elementos se encontram em quantidades ideais.

Para Boro, que apresentou teores médios, foi necessária aplicação de $1 \mathrm{~kg} \mathrm{ha}^{-1}$, sendo aplicados $8,3 \mathrm{~kg} \mathrm{ha}^{-1}$ de bórax, totalizando 2 sacos de $50 \mathrm{~kg}$.

A área onde foi implantada a cultura é composta por 12 ha, acarretando reduzido impacto ambiental negativo. Em decorrência do primeiro ciclo de produção, a área será preparada de modo convencional, com aração e gradagem, ocorrendo escoamento superficial com maior intensidade neste primeiro ciclo. Assim, a partir do segundo ciclo produtivo, em função do plantio direto, os impactos serão mitigados, ocorrendo, também, a redução dos processos de compactação do solo. 
Tabela 3. Análise de solo

\begin{tabular}{|c|c|c|}
\hline Atributo & Unidade & Amostra de solo \\
\hline Ph & & 6,3 \\
\hline $\mathbf{P}$ & \multirow{3}{*}{$\mathrm{mg} \mathrm{dm} \mathrm{m}^{-3}$} & 13 \\
\hline $\mathbf{K}$ & & 180 \\
\hline $\mathrm{Na}$ & & 74 \\
\hline $\mathrm{Ca}^{2+}$ & \multirow{7}{*}{ Cmolc $\mathrm{dm}^{-3}$} & 2,9 \\
\hline $\mathbf{M g}^{2+}$ & & 0,6 \\
\hline $\mathrm{Al}^{3+}$ & & 0,0 \\
\hline $\mathrm{H}+\mathrm{Al}$ & & 2,1 \\
\hline SB & & 4,0 \\
\hline (t) & & 4,0 \\
\hline (T) & & 6,1 \\
\hline P-rem & $\mathrm{Mg} \mathrm{L}^{-1}$ & - \\
\hline Zn & \multirow{6}{*}{$\mathrm{mg} \mathrm{dm}^{-3}$} & 14,1 \\
\hline $\mathrm{Fe}$ & & 279 \\
\hline Mn & & 198 \\
\hline $\mathrm{Cu}$ & & 6,3 \\
\hline B & & 0,71 \\
\hline $\mathbf{S}$ & & 7 \\
\hline
\end{tabular}

Para verificar a viabilidade da implantação da cultura em propriedade de com pivô central, foram estimados os custos e as receitas de 2017 a 2025, com base na produtividade e custos obtidos a partir da colheita de 2016.

O cálculo da receita do milho para o ano de 2016 foi obtido da seguinte maneira: a quantidade produzida (190 sacas/ha) x preço médio x área. Para o ano de 2016, o valor da saca de milho foi de $\mathrm{R} \$ 26,30$. Para a projeção de receita de 2017 , foi utilizada a mesma fórmula de cálculo, considerando preço fixo do milho com valor da média dos últimos 10 anos (R\$22,77), acrescentando, na receita, a inflação média dos últimos 10 anos (6,22\%). De 2018 em diante, foi adicionado 6,22\% (média da inflação dos 10 anos) em relação ao ano anterior. Ao valor do custo de produção foi acrescentado o valor da inflação dos últimos 10 anos, crescendo $6,22 \%$ a cada ano. Em posse das informações de custos e receitas dos próximos anos, foi possível montar um fluxo de caixa e determinar o Payback, que consiste no tempo em que a empresa leva para recuperar o capital inicial investido. Não será levada, em conta nos cálculos, a depreciação anual. (Tabela 4). 
Tabela 4. Média de preço e inflação dos últimos 10 anos.

\begin{tabular}{ccc}
\hline Ano & Preço médio do milho & Inflação \\
\hline 2007 & $\mathrm{R} \$ 19,27$ & $4,46 \%$ \\
2008 & $\mathrm{R} \$ 22,25$ & $5,90 \%$ \\
2009 & $\mathrm{R} \$ 18,35$ & $4,31 \%$ \\
2010 & $\mathrm{R} \$ 17,37$ & $5,91 \%$ \\
2011 & $\mathrm{R} \$ 24,76$ & $6,50 \%$ \\
2012 & $\mathrm{R} \$ 25,14$ & $5,84 \%$ \\
2013 & $\mathrm{R} \$ 23,71$ & $5,91 \%$ \\
2014 & $\mathrm{R} \$ 24,80$ & $6,41 \%$ \\
2015 & $\mathrm{R} \$ 25,70$ & $10,67 \%$ \\
2016 & $\mathrm{R} \$ 26,30$ & $6,29 \%$ \\
Média 10 anos & $\mathrm{R} \$ 22,77$ & $6,22 \%$ \\
\hline
\end{tabular}

\section{Resultados e discussão}

Os recursos fixos e variáveis utilizadas para o projeto são descritos nas tabelas seguintes, Tabela 5, Tabela 6 e Tabela 7.

Tabela 5. Descrição dos componentes de custo fixo.

\begin{tabular}{lcc}
\hline Descrição & Valor & $\%$ \\
\hline Calcário & 782,5 & 0,68 \\
Pivot central & $109.000,00$ & 99,32 \\
Total & $109.782,50$ & 100 \\
\hline
\end{tabular}

Tabela 6. Descrição dos componentes de custo variáveis.

(continua)

\begin{tabular}{lccccc}
\hline \multicolumn{7}{c}{ CUSTO VARIÁVEL } \\
\hline Descrição & Unid. & Quantidade & Valor unitário & Valor em total & $\%$ \\
\hline Nitrogênio - N & Kg & 800 & 3,94 & 3152,00 & 10.16 \\
Fósforo - P2O5 & Saco & 152 & 40,00 & 6080,00 & 19.60 \\
Óxido de Zinco & Saco & 6 & 300,00 & 1800,00 & 5.80 \\
Sulfato de cobre & Saco & 12 & 60,00 & 720,00 & 2.32 \\
Ácido bórico & Saco & 12 & 68,33 & 820,00 & 2.64 \\
Sementes & Saco & 12 & 175,00 & 2100,00 & 6.77 \\
Formicida & $\mathrm{Kg}$ & 2 & 9,15 & 18,30 & 0.059 \\
Herbicida & $\mathrm{L}$ & 8 & 19,42 & 155,36 & 0.50 \\
Inseticida & $\mathrm{L}$ & 4 & 65,59 & 262,36 & 0.85 \\
Espalhante adesivo & $\mathrm{L}$ & 1,2 & 8,44 & 10,13 & 0.033 \\
Energia Elétrica & $\mathrm{Kw} / \mathrm{h}$ & 24000 & 0,20 & 4800,00 & 15.47 \\
\hline
\end{tabular}


Tabela 6. Descrição dos componentes de custo variáveis.

(conclusão)

CUSTO VARIÁVEL

\begin{tabular}{|c|c|c|c|c|c|}
\hline Descrição & Unid. & Quantidade & Valor unitário & Valor em total & $\%$ \\
\hline Calagem geral & $h / h$ & 7 & 120,00 & 840,00 & 2.71 \\
\hline Gradagem & $h / h$ & 17,28 & 120,00 & 2073,60 & 6.68 \\
\hline Plantio & $h / h$ & 14,64 & 120,00 & 1756,80 & 5.67 \\
\hline Adubação de cobertura & $h / h$ & 19,92 & 12,00 & 239,04 & 0.77 \\
\hline Capina mecânica & $h / h$ & 19,92 & 120,00 & 2390,40 & 7.70 \\
\hline Roçada & $h / h$ & 19,92 & 120,00 & 2390,40 & 7.70 \\
\hline Aplicação de inseticidas & $h / h$ & 10,56 & 120,00 & 1267,20 & 4.08 \\
\hline $\begin{array}{l}\text { Custo variável (CV) } \\
\text { Custo operacional } \\
\text { variável (COV) }\end{array}$ & \multicolumn{2}{|c|}{$\mathbf{R} \$$} & $\mathbf{R} \$$ & $\begin{array}{c}30875,59 \\
154,38\end{array}$ & 0,50 \\
\hline Custo variável total (CVT) & \multicolumn{3}{|c|}{$R \$$} & $31.029,97$ & 100 \\
\hline
\end{tabular}

Fonte dos preços: Mercado local de Santa Teresa.

Tabela 7. Fluxo de caixa

\begin{tabular}{lcccc}
\hline & Receitas & Despesas & Saldo & Fluxo acumulado \\
\hline 2016 & $59.964,00$ & $31.029,96$ & $28.934,04$ & $28.934,04$ \\
2017 & $54.511,38$ & $32.960,02$ & 21511,36 & $50.445,40$ \\
2018 & $57.901,99$ & $35.010,13$ & $22.891,86$ & $73.337,26$ \\
2019 & $61.503,49$ & $37.187,76$ & $24.315,73$ & $97.652,99$ \\
2020 & $65.329,00$ & $39.500,83$ & $25.828,17$ & $123.481,16$ \\
2021 & $69.392,46$ & $41.957,78$ & $27.434,68$ & $150.915,84$ \\
2022 & $73.708,67$ & $44.567,55$ & $29.141,12$ & $180.056,96$ \\
2023 & $78.293,35$ & $47.339,65$ & $30.953,70$ & $211.010,66$ \\
2024 & $83.163,20$ & $50.284,18$ & $32.879,02$ & $243.889,68$ \\
2025 & $88.335,95$ & $53.411,86$ & $34.924,09$ & $278.813,77$ \\
\hline
\end{tabular}

Analisando o custo variável total, que é o custo que engloba os insumos, mão de obra, energia, entre outros, verificou-se um valor de $R \$ 31.029,97$, o que dá uma média de $\mathrm{R} \$ 2.585,83$ por hectare. O valor encontrado está dentro dos padrões para propriedades de alta tecnologia no estado, que apresentou, na safra 2015/2016, segundo dados do IMEA, um custo por hectare de $\mathrm{R} \$ 2.422,34$.

O Payback foi definido por 5 anos e 8 meses. Para encontrar os 5 anos, é necessário somar os saldos de cada ano até que o valor se iguale ao valor do investimento inicial. A partir daí, utilizou-se o investimento inicial (Custo variável + Custo Fixo), subtraindo a soma dos 5 anos (2016 a 2020), totalizando $R \$ 17.331,31$. Esse valor foi dividido pelo valor do saldo do sexto ano, totalizando 0,631729985 . Esse valor foi multiplicado por 12 para conseguir o período em meses, resultando em 8 meses. Valor semelhante foi encontrado por Cappellari (2013), com 5 anos e 11 meses. 


\section{CONCLUSÃO}

Conforme os valores encontrados na tabela de fluxo de caixa, verifica-se que a implantação de lavoura de milho com irrigação no município de Santa Teresa é viável, tendo um Payback de 5 anos e 8 meses.

\section{REFERÊNCIAS}

CAPPELLARI, A. Viabilidade Econômica e Financeira para Implantação de Projeto de Irrigação com Pivô Central em Propriedade Agrícola de Tuparendi/RS.

Trabalho de Conclusão de Curso. FEMA, 2013.

CASELA, C. R.; FERREIRA, A. S.; PINTO, N. F. J. A. Doenças na Cultura do Milho. Circular Técnica, n. 83, p. 1-14, 2006. Disponível em:

$<$ https://www.infoteca.cnptia.embrapa.br/bitstream/doc/490415/1/Circ83.pdf >. Acesso em: 19 nov. 2016.

CONAB: Milho, 2017. Disponível

em:<http://www.conab.gov.br/OlalaCMS/uploads/arquivos/

17_05_12_10_37_57_boletim_graos_maio_2017.pdf>. Acesso em: 17 maio 2017.

CRUZ, I.; VIANA, P.A.; WAQUIL, J. M. Pragas da fase vegetativa e reprodutiva. 2013. Disponível

em:<http://www.agencia.cnptia.embrapa.br/gestor/milho/arvore/CONTAG01_69_16820 051120.html>. Acesso em: 19 nov. 2016.

DUARTE, J.O.; GARCIA, J. C. MIRANDA, R.A. Sistema de Produção: Cultivo do Milho. 7. ed., 2011. Disponível em:<http://sistemasdeproducao.cnptia.embrapa.br/FontesHTML/Milho/CultivodoMilho_ 7ed/economia.htm>. Acesso em: 25 de novembro de 2016.

FERRÃO, R. G. et al. 'Capixaba Incaper 203': Nova Variedade de Milho para a Agricultura Familiar do Estado do Espírito Santo. Vitória: Incaper, 2013

PREZZOTI, L. C. et al. Manual de recomendação de calagem e adubação para o Estado do Espírito Santo - $5^{\text {a }}$ aproximação. Vitória: SEEA/INCAPER/CEDAGRO, 2007. 305 p. 